\title{
Clinical Reasons for Returning Hearing Aids
}

\author{
Ju Young Hong ${ }^{1}$, In-Hwan $\mathrm{Oh}^{2}$, Tae Suk Jung ${ }^{1}$, \\ Tae Hyun Kim ${ }^{1}$, Ho Min Kang ${ }^{1}$, and Seung Geun Yeo ${ }^{1}$ \\ ${ }^{1}$ Departments of Otorhinolaryngology-Head and Neck Surgery, ${ }^{2}$ Preventive Medicine, School of Medicine, Kyung Hee University, \\ Seoul, Korea
}

Received October 16, 2013

Revised January 16, 2014

Accepted February 3, 2014

\author{
Address for correspondence \\ Seung Geun Yeo, MD, PhD \\ Department of Otorhinolaryngology- \\ Head and Neck Surgery, \\ School of Medicine, \\ Kyung Hee University, \\ 23 Kyungheedae-ro, \\ Dongdaemun-gu, \\ Seoul 130-872, Korea \\ Tel $+82-2-958-8474$ \\ Fax $+82-2-958-8470$ \\ E-mail yeo2park@gmail.com
}

Background and Objectives: Increases in older aged populations and exposure to complicated noise environments have increased the number of hearing-impaired patients, creating greater demands for hearing aids. We have assessed the reasons that individuals rejected wearing and returned properly prescribed hearing aids, as well as differences in individual factors between younger and elderly adults. Subjects and Methods: Of 1138 patients for whom hearing aids were prescribed at Kyung Hee University Medical Center Hearing Aid Clinic, 81 $(6.14 \%)$ returned their hearing aids, including 36 patients aged $<65$ years and 45 aged $\geq 65$ years. Patient-related, hearing-related, and hearing aid-related factors were assessed by retrospective chart analysis and phone survey and compared in the two groups. Results: The primary symptoms reported by the 81 patients who returned their hearing aids were hearing disturbance, ringing, and fullness in the ear, in that order and in both groups. The rate of hearing aid return was similar in elderly females and males $(p=0.288)$. The spondee recognition threshold was significantly higher in younger than in elderly adults $(63.3 \pm 14.0 \mathrm{~dB}$ vs. $55.6 \pm 14.74$ $\mathrm{dB}, p=0.019$ ), but the hearing aid return rate was highest in patients with moderate hearing loss in both groups. In evaluating the reasons for return of hearing aids, we found that ineffectiveness of the device was the most frequent reason, accounting for $32.0 \%$ of returns, the highest percentage in both groups, with the most frequent patient problem caused by management difficulty in elderly and financial difficulty in younger adults. Conclusions: The reasons for hearing aid return were different in two groups. Financial considerations were cited more by younger adults, while difficulties in managing hearing aids were cited more frequently by elderly adults. Patients in both groups, however, reported that the most frequent reasons for return were inadequate hearing improvement and inconvenience wearing the hearing aid due to noise amplification.

Korean J Audiol 2014;18(1):8-12

\section{Introduction}

Hearing disturbance is defined by difficulties and/or abnormalities in hearing sounds and understanding language. Hearing disturbance is the third most common chronic disease in elderly individuals, following arthritis and high blood pressure. ${ }^{1)}$ Hearing disturbance also occurs in younger individuals, due to their frequent exposure to noise. ${ }^{2)}$ Hearing aids improve hearing by amplifying sound, thus promoting the abil-

This is an Open Access article distributed under the terms of the Creative Commons Attribution Non-Commercial License (http://creativecommons. org/licenses/by-nc/3.0/) which permits unrestricted non-commercia use, distribution, and reproduction in any medium, provided the original work is properly cited. ity of patients to communicate with other people.

The Korea Centers for Disease Control and Prevention recently announced that the prevalence of bilateral hearing disturbance in individuals over age 12 years was $4.5 \%$, increasing to $25.9 \%$ in individuals over age 65 years. After age 50 years, the rate of bilateral hearing disturbance triples every 10 years, being $2.9 \%$ for persons in their $50 \mathrm{~s}, 12.1 \%$ for persons in their $60 \mathrm{~s}$, and $31.7 \%$ for persons aged 70 years and over. However, only $11.3 \%$ of individuals aged $\geq 65$ years with unilateral or bilateral hearing disturbance use hearing aids, with the rate being much lower in females than in males $(7.2 \%$ vs. $17.0 \%)^{3)}$

The National Statistics Service of Korea has estimated that 
$11.8 \%$ of the total population in 2012 were aged $\geq 65$ years and that this percentage will increase to about $24.3 \%$ in $\left.2030 .{ }^{4}\right)$ Thus, interest in and demand for hearing aids for recovery from hearing disturbance are expected to increase. Nevertheless, despite improvements in hearing aid performance, design, and adaptation, the current hearing aid usage rate is still quite low, with an estimated $20 \%$ of patients prescribed hearing aids returning or declining the devices. ${ }^{5)}$

To elucidate the reasons that patients refuse and/or return properly prescribed hearing aids, we analyzed hearing aid usage and the reasons for return in younger ( $<65$ years) and elderly ( $\geq 65$ years) adults.

\section{Subjects and Methods}

Of the 1318 patients who visited the Department of Otolaryngology, Kyunghee University School of Medicine Hearing Aid Clinic and were prescribed hearing aids from January 2000 to November 2012, 81 (6.14\%) returned their hearing aids within 3 months, including 36 patients aged $<65$ years and 45 aged $\geq 65$ years. Using retrospective chart analysis and phone surveys, we compared reasons for returning hearing aids in the two groups. The characteristics of patients with returning hearing aid were subdivided into patient related, hearing related, and hearing aid related factors. Patient related factors included patient age, gender, period of hearing disturbance, and main symptom at the time of hospital visit (hearing disturbance, ringing, or fullness in the ears). Hearing related factors included the results of pure tone audiometry at the time of hearing aid prescription, speech discrimination test, dynamic range, and degree of hearing disturbance, defined as mild (26-40 dB), moderate (41-55 dB), moderately severe (56-70 dB), severe (71-90 dB), and Profound (>90 $\mathrm{dB})$. Hearing aid related factors included hearing aid location: completely in the canal (CIC), in the canal (ITC), in the ear (ITE), behind the ear (BTE), and open type BTE. For analysis, reasons for hearing aid return were subdivided into 2 groups, hearing aid problems and patient problems. Hearing aid problems included ineffective hearing aids, noise (noisiness, vibration), discomfort, and bad sound quality, whereas patient problems included uselessness (e.g. hearing recovery, ill health, death), financial situation, and difficulties managing the hearing aids.

All statistical analyses were performed using the Statistical Package for Social Science 18.0 (SPSS Inc., Chicago, IL, USA). Parameters were compared using the chi-square test and Student's t-test, as warranted. A $p$ value $<0.05$ was defined as statistically significant.

\section{Results}

Of 1318 hearing aid users, 81 (6.14\%), of mean age 65.3 \pm 14.5 years, returned their hearing aids. Mean ages in the younger and elderly adults were $52.6 \pm 11.4$ years and $75.4 \pm$ 6.5 years, respectively. Of the 81 patients, 33 were male and 48 were female, including 17 males and 19 females in the younger adult group and 16 males and 29 females in the elderly group. Although females over age 65 years returned more hearing aids than females under age 65 years, this difference was not statistically significant $(p=0.288)$. The overall duration of hearing disturbance was $7.4 \pm 12.2$ years, $8.8 \pm 14.5$ years in younger adults and $6.3 \pm 10.1$ years in elderly patients $(p=0.373)$. The main symptom at first appearance at the hospital was hearing disturbance, observed in 72 of the 81 patients $(88.8 \%)$, including 32 of $36(88.8 \%)$ younger and 40 of $45(88.8 \%)$ elderly adults. Thirty-five patients (43.2\%), 19 younger $(52.7 \%)$ and 16 elderly $(35.5 \%)$ individuals, reported ringing in the ears, whereas $17(20.9 \%), 9$ younger $(25 \%)$ and 8 elderly adults (17.7\%), reported ear fullness (Table 1).

We found that the overall spondee recognition threshold in all 81 patients was $59.0 \pm 14.9 \mathrm{~dB}, 63.3 \pm 14.0 \mathrm{~dB}$ in younger and $55.6 \pm 14.7 \mathrm{~dB}$ in elderly adults $(p=0.019)$. Mean overall speech discrimination ability was $74.4 \pm 13.8 \%, 75.6 \pm$ $12.1 \%$ for younger and $73.3 \pm 16.1 \%$ for older adults, mean overall most comfortable loudness (MCL) was $82.28 \pm 14.9$, $85.22 \pm 19.1$ for younger and $79.33 \pm 9.3$ for older adults $(p=$

Table 1. Summary of patient characteristics

\begin{tabular}{lcccc}
\hline & Total & Adult & Elderly & $p$-value \\
\hline Number & 81 & $36(44.4 \%)$ & $45(55.6 \%)$ & 0.157 \\
Age (years) & $65.3 \pm 14.5$ & $52.6 \pm 11.4$ & $75.4 \pm 6.5$ & - \\
Sex (M:F) & $33: 48$ & $17: 19$ & $16: 29$ & 0.288 \\
Duration of HD (years) & $7.4 \pm 12.2$ & $8.8 \pm 14.5$ & $6.3 \pm 10.1$ & 0.373 \\
Main symptoms & & & $40(88.8 \%)$ & 1 \\
$\quad$ HD & $72(88.8 \%)$ & $32(88.8 \%)$ & $16(35.5 \%)$ & 0.12 \\
Tinnitus & $35(43.2 \%)$ & $19(52.7 \%)$ & $8(17.7 \%)$ & 0.428 \\
Ear fullness & $17(20.9 \%)$ & $9(25 \%)$ & \\
\hline
\end{tabular}

HD: hearing disturbance 
Table 2. Results of hearing test in younger and elderly adults

\begin{tabular}{lcccc}
\hline & Total & Adult & Elderly & $p$-value \\
\hline PTA (dB) & $59.0 \pm 14.9$ & $63.3 \pm 14.0$ & $55.6 \pm 14.75$ & $0.019^{*}$ \\
SDS (\%) & $74.44 \pm 13.8$ & $75.56 \pm 12.1$ & $73.33 \pm 16.1$ & 0.745 \\
MCL & $82.28 \pm 14.9$ & $85.22 \pm 19.1$ & $79.33 \pm 9.3$ & 0.419 \\
UCL & $102.39 \pm 9.2$ & $104.11 \pm 11.2$ & $100.67 \pm 7.0$ & 0.443 \\
DR & $49.3 \pm 17.4$ & $49.1 \pm 21.0$ & $49.6 \pm 14.22$ & 0.948 \\
\hline
\end{tabular}

* $p<0.05$. PTA: pure tone audiometry, SDS: speech discrimination score, MCL: most comfortable loudness, UCL: uncomfortable loudness, DR: dynamic range

Table 3. Hearing disturbance grade in younger and elderly adults returning hearing aids for refund

\begin{tabular}{lcccc}
\hline & Total & Adult & Elderly & p-value \\
\hline Mild & $8(9.8 \%)$ & $0(0 \%)$ & $8(17.7 \%)$ & - \\
Moderate & $30(37 \%)$ & $14(38.8 \%)$ & $16(35.5 \%)$ & 0.758 \\
Moderate-severe & $25(30.8 \%)$ & $12(33.3 \%)$ & $13(28.8 \%)$ & 0.667 \\
Severe & $17(20.9 \%)$ & $9(25 \%)$ & $8(17.7 \%)$ & 0.428 \\
Profound & $1(1.2 \%)$ & $1(2.8 \%)$ & $0(0 \%)$ & - \\
\hline Total & $81(100 \%)$ & $36(100 \%)$ & $45(100 \%)$ & \\
\hline
\end{tabular}

Table 4. Degree of hearing loss and type of hearing aids in younger and elderly adults returning hearing aids for refund

\begin{tabular}{lcccccc}
\hline & $\begin{array}{c}\mathrm{CIC} \\
\text { (adult/elderly) }\end{array}$ & $\begin{array}{c}\text { ITC } \\
\text { (adult/elderly) }\end{array}$ & $\begin{array}{c}\text { ITE } \\
\text { (adult/elderly) }\end{array}$ & $\begin{array}{c}\text { BTE } \\
\text { (adult/elderly) }\end{array}$ & $\begin{array}{c}\text { Open type } \\
\text { (adult/elderly) }\end{array}$ & $\begin{array}{c}\text { Total } \\
\text { (adult/elderly) }\end{array}$ \\
\hline Mild & $4(0 / 4)$ & $2(0 / 2)$ & $0(0 / 0)$ & $0(0 / 0)$ & $2(0 / 2)$ & $8(0 / 8)$ \\
Moderate & $11(7 / 4)$ & $13(5 / 8)$ & $2(0 / 2)$ & $1(0 / 1)$ & $3(2 / 1)$ & $30(14 / 16)$ \\
Moderate-severe & $6(3 / 3)$ & $16(7 / 9)$ & $0(0 / 0)$ & $1(1 / 0)$ & $2(1 / 1)$ & $25(12 / 13)$ \\
Severe & $1(0 / 1)$ & $10(7 / 3)$ & $1(0 / 1)$ & $3(1 / 2)$ & $2(1 / 1)$ & $17(9 / 8)$ \\
Profound & 0 & 0 & 0 & $1(1 / 0)$ & 0 & $1(1 / 0)$ \\
\hline Total & $22(10 / 12)$ & $41(19 / 22)$ & $3(0 / 3)$ & $6(3 / 3)$ & $9(4 / 5)$ & $81(36 / 45)$ \\
\hline
\end{tabular}

CIC: completely in the canal, ITC: in the canal, ITE: in the ear, BTE: behind the ear

Table 5. Reasons for returning hearing aids

\begin{tabular}{|c|c|c|c|c|}
\hline & Total & Adult & Elderly & p-value \\
\hline \multicolumn{5}{|l|}{ Problem of hearing aids } \\
\hline Ineffectiveness & $26(32.0 \%)$ & 10 & 16 & 0.456 \\
\hline Noise & $19(23.4 \%)$ & 7 & 12 & 0.446 \\
\hline Uncomfotable wearing sensation & $14(17.2 \%)$ & 9 & 5 & - \\
\hline Poor sound quality & $3(3.7 \%)$ & 1 & 2 & - \\
\hline \multicolumn{5}{|l|}{ Problem of patient } \\
\hline Difficulty of management & $8(9.8 \%)$ & 1 & 7 & - \\
\hline Financial reasons & $6(8.6 \%)$ & 5 & 1 & - \\
\hline Out of use & $5(6.1 \%)$ & 3 & 2 & - \\
\hline
\end{tabular}

0.419), mean overall uncomfortable loudness (UCL) was $102.39 \pm 9.2,104.11 \pm 11.2$ for younger and $100.67 \pm 7.0$ for older adults ( $p=0.443$ ); and mean overall dynamic range was $49.3 \pm 17.4 \mathrm{~dB}, 49.1 \pm 21.0 \mathrm{~dB}$ for younger and $49.6 \pm 14.2$ $\mathrm{dB}$ for older patients $(p=0.948)$ (Table 2$)$.

Assessment of the degree of hearing disturbance in the 81 patients who returned their hearing aids found mild, moderate, moderately severe, severe, and profound deafness in 8 (9.8\%), 30 (37\%), 25 (30.8\%), 17 (20.9\%), and 1 (1.2\%) pa- tients, respectively. These degrees of hearing disturbance were observed in 0 (0\%), 14 (38.8\%), 12 (33.3\%), 9 (25\%), and 1 $(2.8 \%)$, respectively, of the younger group, and in $8(17.7 \%)$, $17(35.5 \%), 13(28.8 \%), 8(17.7 \%)$, and $0(0 \%)$, respectively, of the older group (Table 3 ).

Types of hearing aids returned included 22 CIC type, 41 ITC type, 3 ITE type, 6 BTE type, and 9 open type. In the younger group, these types were returned by 10, 19, 0, 3, and 4 patients, respectively, whereas, in the older group, these 
types were returned by $12,22,3,3$, and 5 patients, respectively (Table 4).

Reasons for return could be we divided into hearing aid problems and patient problems. The most frequent hearing aid problem was ineffectiveness, reported by 26 patients $(32.0 \%)$, 10 in the younger and 16 in the elderly group. Other hearing aid problems included noise, reported by 19 patients $(23.4 \%)$, 7 in the younger adult and 12 in the elderly group; wearing discomfort, cited by 14 patients (17.2\%), 9 in the younger and 5 in the elderly group; and poor sound quality, mentioned by 3 patients (3.7\%), 1 in the younger and 2 in the elderly group. Patient problems included management difficulty in 8 patients $(9.8 \%), 1$ in the younger and 7 in the elderly group (2 male and 5 female patients); financial difficulty in 6 patients $(8.6 \%), 5$ in the younger and 1 in the elderly group; and uselessness (e.g. hearing recovery, poor health, death) in 5 patients $(6.1 \%), 3$ in the younger and 2 in the elderly group (Table 5).

\section{Discussion}

Hearing loss results in partial severance of communication via speaking and language and information exchange, resulting in considerable inconvenience in daily life and negative mental and/or emotional effects. Patients who experience hearing loss can therefore benefit substantially from hearing aids. The degree of noise in modern society has increased the number of hearing-impaired individuals. Moreover, people are living to an older age, increasing the population of elderly individuals. Thus, the demand for hearing aids is expected to increase dramatically in the future. In Korea, $7.2 \%$ of the total population in 2000 was over 65 years of age, and this percentage is expected to increase to $14.5 \%$ by $2018 .{ }^{6}$ In 2011 , it was estimated that only $13 \%$ of individuals with hearing disorders who required hearing aids had been prescribed hearing aids, fewer than the $25 \%$ in countries such as the USA and other European countries. ${ }^{7-9)}$ Nevertheless, the market for hearing aids has grown continuously, due to increases in the population of elderly individuals and their income level, as well as to the development of medical devices, and this market is expected to increase in the next few decades.

Despite advances in hearing aid development and technology, $3 \%$ to $16 \%$ of patients prescribed hearing aids return the devices. ${ }^{10)}$ Factors associated with adaptation to hearing aids include younger age, strong desire for rehabilitation, ${ }^{11)}$ and mild deafness. Regular visits to the hospital for hearing aid adaptation and adjustment have been associated with good hearing rehabilitation. ${ }^{12)}$ Adaptation to and benefits from hearing aids have been associated with degree of education, hearing aid type and price, battery price, wearing hearing aids daily for a certain period of time, and horizontal shape of the hearing aid. ${ }^{13-17)}$ We found, however, that, despite hearing aid prescription, consultation, and fitting processes by experts, 81 of $1318(6.14 \%)$ patients prescribed hearing aids returned their devices within 3 months. Females were more likely to return hearing aids than males (59.2\% vs. $40.8 \%$ ), especially when females and males over age 65 years were compared. Elderly women may be less familiar with the operation of their devices and be less involved in social life than men with hearing aids, making elderly women less sure about the necessity of wearing hearing aids. These findings suggest that attention should be paid to hearing aid prescription and management in women, especially elderly women.

In general, the spondee recognition threshold is lower in younger than in elderly adults. Age has been found to correlate with the severity of deafness, making the threshold higher in elderly patients due to hearing aid failure. In contrast, we found that the spondee recognition threshold was higher in the younger than in the elderly group. This may have been due to our selection of ITC type rather than BTE or ITE type hearing aids for patients with severe deafness, due to the better appearance of the ITC type. Other characteristics of the 2 groups were similar, including speech discrimination ability, UCL, MCL, and dynamic range. The return rate by both groups was highest for individuals with moderate hearing loss, followed by individuals with moderately severe and severe hearing loss.

When we assessed hearing aid related factors, we found that the rates of return of each hearing aid type were similar in the two groups. This may have resulted from our consideration of patient preference, including allowing the patient to make the decision on hearing aid type.

In evaluating the reasons for return of hearing aids, we found that ineffectiveness of the device was the most frequent reason, accounting for $32.0 \%$ of returns, the highest percentage in both groups. Noises, including acoustic feedback, occlusion effect, over-amplification, surrounding noise, and sound transformation, accounted for $23.4 \%$ of returns. Our finding, that hearing aid return was due in large part to hearing aid ineffectiveness and hearing aid noises, indicates that hearing recovery in patients with hearing disturbance is limited and that hearing aid technology is not sufficiently developed to result in a normal hearing level.

Patient problems were associated with difficulties encountered by elderly individuals in managing hearing aids. These patients usually do not adapt easily to new technology, have less sensitive sensations in their hands, find handling small hearing aids difficult, delay repairing their hearing aids, and are unfamiliar with handling hearing aids, despite repeated 
consultations and education. Moreover, they find it harder to recognize and see objects than younger adults. Whereas 52.4\% of patients hesitated to purchase hearing aids due to inconvenience, $51.2 \%$ were reluctant for financial reasons. We found, however, that few elderly individuals returned their hearing aids for financial reasons, since many of their healthcare expenses were paid by their children. In contrast, most of the younger adults likely had to pay these expenses themselves.

Hearing aid return ratios may be reduced by adequate medical consultation, including a diagnosis of the reason for deafness, proper hearing tests to determine the type and degree of deafness, and to choose the optimal hearing aid for hearing improvement. Follow-up measures after hearing aid prescription should include a continuous hearing rehabilitation service. Periodic consultations and education may help solve problems and minimize any inconvenience, allowing patients to adapt to hearing aids.

\section{Conclusion}

Although hearing aid return rates were similar in younger and elderly adults, but the reasons showed different tendency. Financial considerations were cited more by younger adults, while difficulties in managing hearing aids were cited more frequently by elderly adults. Patients in both groups, however, reported that the most frequent reasons for return were inadequate hearing improvement and inconvenience wearing the hearing aid due to noise amplification.

\section{Acknowledgments}

This work was supported by the National Research Foundation of Korea (NRF) grant funded by the Korea government (MSIP)(No. 2011-0030072).

\section{REFERENCES}

1) Chae SW. A review of age-related hearing loss. J Korean Med Assoc 2011;54:908-9.

2) Na WS, Kim KW, Jung SD, Lee JW, Jung JY, Suh MW. Effect of active noise cancelling earphones on preferred listening level when listening to portable music players in noisy environments. Korean J Otorhinolaryngol-Head Neck Surg 2012;55:415-21.

3) Cho YS, Choi SH, Park KH, Park HJ, Kim JW, Moon IJ, et al. Prevalence of otolaryngologic diseases in South Korea: data from the Korea National Health and Nutrition Examination Survey 2008. Clin Exp Otorhinolaryngol 2010;3:183-93.

4) Statistics Korea. Statistics for the elderly 2012. Daejeon: Statistics Korea. Available from: http://kostat.go.kr/portal/korea/kor_nw/3/ index.board?bmode.

5) Storm K. The Hearing Review. Annual review of the hearing aid industry. Fenton, MI: Allied Media;2013.

6) Korea Research Institute for Local Administration. A study on share and management system of welfare finance for aged society. Seoul: Korea Research Institute for Local Administration;2006. Available from: http://www.krila.re.kr/common/filedown.asp?ix=7221.

7) Ministry of Health and Welfare. The result of disability survey 2011. Seoul: Ministry of Health and Welfare;2011. Available from: http:// www.bokjiro.go.kr/cmm/fms/FileDown.do?atchFileId=5826892.

8) Korea Centers for Disease Control and Prevention. The Korea National Health and Nutrition Examination Survey 2009. Cheongwon: Korea Centers for Disease Control and Prevention;2011.

9) Hüls R. Der Markt für Hörsysteme. Hamburg: Innocentia-Verlag; 2004.

10) Kochkin, S, Beck DL, Christensen ALA, Medwetsky L, Northern J, Sweetow R. MarkeTrak VIII: Why consumers return hearing aids: A guide for reducing hearing aid returns. Washington, DC: Better Hearing Institute;2012.

11) Brooks DN. The time course of adaptation to hearing aid use. Br J Audiol 1996;30:55-62.

12) Wilson C, Stephens D. Reasons for referral and attitudes toward hearing aids: do they affect outcome? Clin Otolaryngol Allied Sci 2003; 28:81-4.

13) Mulrow CD, Tuley MR, Aguilar C. Correlates of successful hearing aid use in older adults. Ear Hear 1992;13:108-13.

14) Hosford-Dunn H, Halpern J. Clinical application of the SADL scale in private practice II: predictive validity of fitting variables. Satisfaction with Amplification in Daily Life. J Am Acad Audiol 2001;12:1536.

15) Warland A, Tonning F. Factors to consider when in-the-canal hearing instruments are used in aural rehabilitation. Scand Audiol 1993; 22:47-55.

16) Beamer SL, Grant KW, Walden BE. Hearing aid benefit in patients with high-frequency hearing loss. J Am Acad Audiol 2000;11:42937.

17) Yun DH, Yoon TH, Lee KS. Subjective satisfaction in hearing aid users by APHAB. Korean J Otolaryngol-Head Neck Surg 2000;43: 698-702. 